ПОЛЯЧЕНКОВ Антон Вадимович - стажер Дипломатической академии Министерства иностранных дел Российской Федерации (119034, Россия, г. Москва, ул. Остоженка, 53/2, стр. 1; tony.fielding@yandex.ru)

\title{
АФРИКАНСКОЕ НАПРАВЛЕНИЕ ВНЕШНЕЙ ПОЛИТИКИ ГЕРМАНИИ В ИССЛЕДОВАНИЯХ НЕМЕЦКИХ АНАЛИТИЧЕСКИХ ЦЕНТРОВ
}

Аннотация. В статье рассматривается роль аналитических центров в формировании африканского направления внешней политики Германии. Автор дает обзор истории развития взаимоотношений между Германией и странами Африки, показывает, каким образом была сформирована нынешняя политика Берлина в данном направлении. В статье рассматриваются деятельность немецких аналитических центров, их рекомендации по поводу того, как следует выстраивать отношения с Африканским континентом; анализируется их влияние на крупные немецкие инициативы, такие как «План Маршалла для Африки». Автор делает вывод о значимости экспертного обеспечения данного направления внешней политики Германии.

Ключевые слова: Германия, Африка, внешняя политика, аналитические центры, план Маршалла

\section{Введение}

Формирование внешнеполитической стратегии государства - достаточно комплексный процесс, который складывается из совокупности различных факторов, среди которых ведущую роль играют национальные интересы. При этом особого внимания заслуживает выбор того или иного направления внешней политики и обоснование этого выбора, тем более в том случае, когда речь идет об относительно новом направлении.

Ярким примером могут послужить отношения между Германией и странами Африки южнее Сахары. Германская империя обладала рядом колоний на континенте, которые она вынуждена была отдать после Первой мировой войны. В дальнейшем Африка не представляла интереса для Германии вплоть до начала XXI в. [Engel 2005]. А буквально несколько лет назад произошли существенные изменения в подходах к выстраиванию отношений с Африканским континентом, в результате чего связи со странами Африки начинают укрепляться, создаются многочисленные программы, направленные на их развитие.

Если попытаться ответить на вопрос, что стало толчком для такого разворота в сторону Африки, можно предположить, что в какой-то момент эксперты проанализировали потенциальные направления внешней политики Германии, в результате чего африканское направление оказалось в числе наиболее перспективных. Такую работу могут провести либо эксперты из аналитических ведомств при Министерстве иностранных дел Германии или других правительственных органов, либо эксперты влиятельных в стране аналитических центров. С учетом того, что последние играют достаточно важную роль в процессе принятия внешнеполитических и внутриполитических решений в Германии, важно понять, какую роль они сыграли в развитии этого направления и почему эта роль была именно такой. Опыт взаимодействия немецких аналитических центров будет полезен и другим странам, в первую очередь России, которая может перенять некоторые удачные черты, учитывая при этом проблемы и недостатки, и значительно усовершенствовать свою систему экспертного обеспечения внешней политики.

Ключевой исследовательский вопрос статьи заключается в том, оказывает ли 
экспертная деятельность аналитических центров Германии влияние на формирование африканского направления внешней политики страны.

\section{История развития отношений между Германией и странами Африки}

Датой начала отношений Германии и стран Африки традиционно принято считать 1884 г., когда в рамках Берлинской конференции по Африке был пересмотрен вопрос о европейских колониях на континенте, в результате чего только что образованной Германии досталась территория нынешних Ганы, Камеруна, Танзании, Намибии, Уганды и Того ${ }^{1}$. Однако для канцлера Бисмарка колонии были только необходимостью подчеркнуть статус империи: он не придавал им важного практического значения, фокусируясь на европейской политике. Точно так же поступали и его преемники [Mair 2005].

После Первой мировой войны Германия лишилась колоний и надолго отодвинула африканское направление внешней политики на второй план. Нормальные отношения со странами Африки стали выстраиваться только после 1990 г. При этом приоритетным направлением являлся юг континента, где расположены наиболее экономически развитые страны. В целом же политика Германии в отношении Африки сводилась скорее к содействию развитию континента, помощи в борьбе с бедностью. Данная стратегия формировалась еще в 70-е гг. XX в., была переосмыслена в 90-е и в 2000 г. получила оформление в виде рабочего документа «Установление основных моментов сотрудничества в сфере развития» [Koepf 2015]. Согласно этому документу, Африка именовалась «континентом бедности», поэтому Германия считала необходимым оказывать гуманитарную помощь, способствовать развитию инфраструктуры и обеспечивать страны необходимыми ресурсами. Таким образом не только решался ряд глобальных проблем в гуманитарной сфере, но и обеспечивалась безопасность на континенте и во всем мире, т.к. повышение доходов населения и уровня их жизни ликвидировало ряд предпосылок для возможных конфликтов.

Данный подход просуществовал до 2003 г., после чего среди немецкого политического истеблишмента произошел переход к идее о том, что Африка - это «кризисный континент». Это было связано с тем, что сразу в нескольких государствах континента вспыхнула гражданская война. Нестабильная обстановка могла вызвать рост организованной преступности и создание террористических группировок, которые могли представлять опасность для Германии. В связи с этим был принят новый план действий, получивший название «Предотвращение гражданских войн, разрешение конфликтов и консолидация мира» ${ }^{2}$. Он был принят в 2004 г. и заключался в создании программ по оказанию необходимой гуманитарной помощи, политическому урегулированию и сотрудничеству в решении накопившихся проблем. При этом Германия отказывалась от идеи прямого военного вмешательства в африканские конфликты. Данный план провалился, поскольку ниша обеспечения африканской безопасности была занята другими странами.

В 2008 г. появляется принципиально новый дискурс в отношении Африки. В связи с активным экономическим ростом и развитием ряда стран появляется концепция «континента возможностей», что предполагало активное торговоэкономическое и инвестиционное сотрудничество, которое было бы взаимовыгодным, позволило бы Германии укрепить свои позиции на африканском рынке и в будущем получать существенные преимущества в торговле и инве-

\footnotetext{
${ }^{1}$ Deutschland-Afrika Beziehungen wärmen sich auf. - Germany-Africa Business Forum. 17.01.2017 Доступ: http://de.germanyafrica.com/deutschland-afrika-beziehungen-warmen-sich-auf/ (проверено 19.03.2019).

2 Aktionsplan „Zivile Krisenprävention, Konfliktlösung und Friedenskonsolidierung“. 2004. Доступ: http://www.konfliktbearbeitung.net/downloads/file1215.pdf (проверено 19.03.2019).
} 
стициях. Данная концепция была принята не сразу и рассматривалась как один из возможных путей выстраивания немецко-африканского сотрудничества. Однако к 2010 г. стало понятно, что у немецкого Министерства иностранных дел и Министерства экономики отсутствует даже единый взгляд на африканское направление внешней политики. Ответственность за это была возложена на МИД, от которого требовалось теперь составить единую стратегию, отражавшую интересы Германии на континенте.

Разработка и согласование плана заняло год, и в 2011 г. МИД Германии представил «Африканскую концепцию федерального правительства». Германия определяла в качестве приоритетных направлений обеспечение безопасности, защиту прав человека, продвижение демократических ценностей, а также всестороннее торгово-экономическое, инвестиционное и энергетическое сотрудничество. На сегодняшний день африканская концепция немецкой внешней политики почти не претерпела изменений. Ее реализация осуществляется через различные проекты, осуществляемые соответствующими министерствами.

Одним из наиболее крупных проектов последних лет является так называемый африканский план Маршалла, по сути развивающий общую африканскую стратегию и заключающийся в экономической помощи странам континента, направлении туда инвестиционных потоков для развития африканских стран [Кукарцева 2018: 157], продвижении демократических ценностей. Успешная реализация данного плана позволит Германии не просто укрепить свои позиции в Африке, но и создать основу для новой, более конкретной и проработанной концепции немецко-африканского сотрудничества ${ }^{1}$.

\section{Роль аналитических центров в отношениях Германии и Африки}

Рассматривая экспертное обеспечение африканского направления внешней политики Германии, можно прийти к выводу, что большинство нынешних инициатив и проектов есть результаты деятельности аналитических центров Германии. Активизация деятельности экспертов этих центров началась в 20142015 гг., когда в Европе начался миграционный кризис. Одновременно с разработкой мер по предотвращению кризиса ряд исследователей решили обратить внимание на его причины и способы решения имеющихся проблем. Так как основная масса мигрантов приходила из Сирии, Ирака, Афганистана и стран Африки, нужно было понять, почему они бегут и что сделать, чтобы они оставались в своих странах.

Найти способ решения проблемы в первых трех случаях оказалось не так просто, а вот для Африки, казалось бы, можно было выработать решения. Вскоре аналитики выработали относительно универсальный взгляд на вещи, который достаточно полно резюмирован в статье Немецкого института международных отношений и вопросов безопасности «Улучшенное управление миграцией» [Angenendt, Kipps 2017]. В статье говорилось, что чаще всего миграционные процессы вызваны войнами или стихийными бедствиями, а если обстановка в странах относительно нормальная, то миграция является следствием низкого уровня жизни. Если повысить уровень жизни в тех странах, откуда приходят мигранты, можно сократить их поток. В выигрыше от этого будут все. При этом авторы статьи конкретизировали, что данный механизм актуален как раз для стран Африки. Если европейские страны, в первую очередь Германия, будут делать инвестиции в экономику стран Африки и развивать местную инфраструктуру, они смогут повысить уровень благосостояния, увеличить число

\footnotetext{
${ }^{1}$ Ein Marshallplan mit Afrika. - Bundesministerium für wirtschaftliche Zusammenarbeit und Entwicklung. Доступ: http://www.bmz.de/de/laender_regionen/marshallplan_mit_afrika/index.jsp (проверено 19.03.2019).
} 
рабочих мест, стимулировать развитие экономики. В результате на выходе та же Германия получит перспективного торгового партнера1.

При этом, несмотря на понимание того, в чем заключается проблема и как она может быть реализована на практике, ни один из влиятельных аналитических центров Германии, входящих в топ рейтингов, не выступил с инициативой возможной практической реализации имеющихся наработок. Ответственность на себя взял Экономический совет Германии - структура, которая объединяет исследователей и политиков и именует себя аналитическим центром будущего, или do-tank (центр действия), поскольку, по их словам, Совет ориентирован больше на практическую реализацию проектов, чем на теоретические исследования ради аналитики.

Именно этот центр совместно с Римским клубом в ноябре 2016 г. представил министру экономического развития Герду Мюллеру проект плана Маршалла для Африки 2 . Суть проекта состояла в инвестициях в экономику стран Африки, прежде всего в энергетику и инфраструктуру. Это позволит стимулировать развитие экономик африканских стран и, помимо прочего, остановит миграционные потоки, т.к. возросший уровень благосостояния и перспективы еще большего экономического процветания будут удерживать население на континенте. В обмен на это Германия получает возможность использовать потенциал Африки для собственной выгоды. К примеру, Африка обладает всем необходимым для развития энергетики, источниками которой служат неисчерпаемые ресурсы вроде солнечного света или ветра. Если инвестировать в эту отрасль, континент вполне может стать новым энергетическим центром, который поможет той же Германии освободиться от зависимости от традиционных источников топлива и энергии.

В феврале 2017 г. план был официально представлен на саммите «Большой двадцатки», причем практически в том же виде, в котором его предложил Экономический совет. Примечательно, что презентация прошла на совещании аналитических центров стран «двадцатки», председателем которой на тот момент была Германия ${ }^{3}$. Это был достаточно интересный ход, который подчеркивал значимость центров и их экспертного анализа в развитии отношений между Африкой и Германией, тем более что в рамках совещания обсуждалось еще достаточно много вопросов сотрудничества между этими двумя акторами [Кукарцева 2018: 158].

C публикацией плана активизировались дискуссии по поводу его целесообразности. Кроме СМИ, в полемику вступили представители аналитических центров, не поддерживающих подобный подход в отношении африканского направления политики. В частности, они высказывали идею о том, что увеличение финансирования вряд ли приведет к уменьшению миграционных потоков, поскольку развитие стран Африки - это все же перспектива, хоть в некоторых случаях и краткосрочная, а население хочет иметь стабильный доход и достойный уровень жизни прямо сейчас, ничего не дожидаясь. К тому же не все сводится только к экономическому процветанию. Защита прав и свобод, демократизация общества и ряд других политических факторов играют важную

\footnotetext{
${ }^{1}$ Migration Study: Europe Needs to Understand the African Context. - Deutsche Welle. 21.04.2018. URL: https://www.dw.com/en/migration-study-europe-needs-to-understand-the-african-context/a-43475220 (accessed 19.03.2019).

2 Sandner P. Deutschlands Marshallplan - Afrikas Skepsis. - Deutsche Welle. 14.11.2016. Доступ: https:// www.dw.com/de/deutschlands-marshallplan-afrikas-skepsis/a-36394167 (проверено 19.03.2019).

3 Thomas Silberhorn stellt Marshallplan mit Afrika in Johannesburg vor. - Bundesministerium fürwirtschaftliche Zusammenarbeit und Entwicklung. 2017. Доступ: http://www.bmz.de/de/presse/aktuelleMeldungen/2017/ februar/170201_pm_012_Thomas-Silberhorn-stellt-Marshallplan-mit-Afrika-in-Johannesburg-vor/index.jsp (проверено 19.03.2019).
} 
роль в мотивации людей покинуть страны Африки в пользу Европы. В противном случае может повториться ливийский сценарий, когда в целом благополучное государство рухнуло из-за недовольства жесткой политикой Каддафи [Angenendt, Martin-Shields, Schraven 2017].

Впрочем, данная точка зрения, по-видимому, не оказала серьезного влияния на африканское направление политики, т.к. основные идеи, заложенные в плане Маршалла для Африки, продолжают лежать в основе немецкого курса1. Видимо, руководство страны считает, что с инвестициями и приходом немецкого бизнеса в Африку можно будет наладить систему продвижения демократических ценностей, таким образом решая две проблемы сразу. Кроме того, ставка также делается на тех мигрантов, которые потом вернутся домой и захотят преобразований. И если кто-то из них за эти преобразования возьмется, использовать они будут как раз опыт немецкой демократии.

В целом, на этом вклад аналитических центров в развитие политики Германии в Африке заканчивается, но не потому, что экспертам нечего сказать, а потому, что партнерство пока больше ничего не предполагает. Рассматривая современное состояние экспертного обеспечения данного направления политики, можно прийти к выводу, что в ближайшее время изменения в данной сфере вряд ли последуют. Задача экспертов будет сводиться к расчетам целесообразности инвестирования в ту или иную сферу. Остальные направления политики Германия пока вряд ли будет развивать.

При этом может возникнуть сценарий, при котором план Маршалла провалится, не оправдав ожиданий немецкого руководства и инвесторов. Уже сейчас выделяются проблемы, которые могут препятствовать реализации плана в полной мере и требуют своего решения, в т.ч. со стороны экспертов. М.А. Кукарцева выделяет два основных вызова. Первый заключается в потенциальной возможности поддержки авторитарных режимов. При этом Германии придется либо вырабатывать программу для улучшения ситуации с правами и свободами человека в этих странах, что потребует дополнительных затрат, либо отказываться от помощи таким странам, что повредит интересам самой Германии [Кукарцева 2018: 159].

Кроме того, некоторые страны обеспокоены тем, что им навязывают немецкую экономическую стратегию, и это при том, что собственной стратегии у таких стран нет. С одной стороны, это затрудняет реализацию немецкого проекта, а с другой - оставляет нерешенными множество проблем [Кукарцева 2018: $160]$.

Экспертам нужно обратить внимание политиков на эти проблемы и выработать механизмы их решения. В противном случае колоссальные ресурсы и усилия, затраченные на немецкий план Маршалла, окажутся потраченными вПустую.

\section{Заключение}

Подводя итог рассмотрения немецкой внешней политики в сфере сотрудничестве с Африкой, необходимо учитывать следующее. Во-первых, эта политика будет полностью выстроена вокруг экономического сотрудничества, и вряд ли это изменится в ближайшее время. И во-вторых, аналитические центры и их деятельность будут играть важную, если не ключевую роль в формировании немецкого курса, вырабатывая соответствующие стратегии поведения и рассчитывая наиболее выгодные для Германии шаги.

\footnotetext{
1 Migrationspolitik: Merkel will Partnerschaft mit Afrika - ohne nennenswerte Selbstkritik zu üben. $R T$ Deutsch. 16.08.2018. Доступ: https://deutsch.rt.com/afrika/74571-migration-eindammen-merkel-willpartnerschaft-aber-fehler/ (проверено 19.03.2019).
} 
При этом стоит помнить, что, несмотря на то что правительство страны, выстраивая свою политику, опирается на рекомендации центров, в ее основе все равно будет оставаться субъективный взгляд политиков и их идеи, основанные не на данных экспертного анализа, а на прагматическом понимании целесообразности тех или иных решений. Является ли такой подход правильным - судить сложно. Однако не стоит полагать, что это каким-то образом принижает значимость аналитических центров. Их деятельность не сводится к государственному заказу, а представляет собой выражение собственного взгляда на проблему, а уже руководство страны решает, придерживаться ли им такого взгляда или нет. В любом случае такая политика будет подкреплена данными экспертного анализа, что значительно уменьшит возможность ее провала. Это, пожалуй, один из основных тезисов, который стоит взять на вооружение странам, желающим перенять немецкий опыт, в особенности России. Если дать экспертам возможность выработать возможные проекты политического курса в той или иной сфере, а потом опираться на них, можно достичь куда большего, чем при той системе принятия решений, которая существует в Российской Федерации на данный момент.

В современном мире, где подчас с мнением экспертов либо не считаются вовсе, либо оказывают на это мнение влияние с помощью финансирования или иных рычагов давления, активное взаимодействие между политиками и учеными - большой шаг вперед. И это не может не радовать.

\section{Список литературы}

Кукарцева М.А. 2018. Гуманитарная политика ЕС в Африке и миграционный кризис. - Контуры глобальных трансформаций: политика, экономика, право. T. 11. № 5. C. 142-163.

Angenendt S., Kipps D. 2017. Better Migration Management. - German Institute for International and Security Affairs. URL: https://www.swp-berlin.org/fileadmin/ contents/products/comments/2017C33_adt_kpp.pdf (accessed 19.03.2019).

Angenendt S., Marton-Shields C., Schraven B. 2017. Mehr Entwicklung - mehr Migration? - German Institute for International and Security Affairs. Доступ: https:// www.swp-berlin.org/fileadmin/contents/products/aktuell/2017A69_adt_etal.pdf (проверено 19.03.2019).

Engel U. 2005. Deutschland, Afrika und die Entstehung gemeinsamer Interessen. - Aus Politik und Zeitgeschichte. 17.01. Доступ: http://www.bpb.de/apuz/29267/ deutschland-afrika-und-die-entstehung-gemeinsamer-interessen? $\mathrm{p}=$ all $($ проверено 19.03.2019).

Koepf T. 2015. Deutschland auf der Suche nach einer Afrika-Strategie. - Note Du Cerfa. Доступ: https://www.ifri.org/sites/default/files/atoms/files/note_du_ cerfa_119_de.pdf (проверено 19.03.2019).

Mair S. 2005. Bedeutung Afrikas für Deutschland. - Aus Politik und Zeitgeschichte. 21.05. Доступ: http://www.bpb.de/internationales/afrika/afrika/59102/deutscheinteressen? $\mathrm{p}=$ all (проверено 19.03.2019). 
POLYACHENKOV Anton Vadimovich, Intern at the Diplomatic Academy of the Ministry of Foreign Affairs of the Russian Federation (bld. 1, 53/2 Ostozhenka St, Moscow, Russia, 119034; tony.fielding@yandex.ru)

\title{
AFRICAN DIRECTION OF THE GERMAN FOREIGN POLICY IN THE STUDIES OF THE GERMAN THINK TANKS
}

\begin{abstract}
The article considers the role of German think tanks and their studies in the national foreign policy decisionmaking process, particularly in its African direction. The author observes the evolution of the Germany's approach to Africa, and reviews the major steps and documents, regulating the policy according to the national interests and political situation in African region. He points out that the interest of German's government in developing the relations with African countries has increased during the last two decades, first because of the security concerns and then because of understanding of the continent's capabilities and potential. The paper demonstrates how the experts have influenced the decision-making process and shaped this foreign policy direction. In particular, the author analyzes German Marshall Plan for Africa, shows its origins, especially the fact that it was developed by the experts of one of the economic think tanks. In conclusion, he shows the prospects of expert's participation in future decision-making.

Keywords: Germany, Africa, foreign policy, think tanks, decision making, Marshall Plan
\end{abstract}

